\title{
ANALISIS PENGARUH CITRA MEREK, BUKTI FISIK, KEHANDALAN, DAN JASA PORTOFOLIO TERHADAP KEPUASAN NASABAH TABUNGAN SIMPEDES PADA PT BANK RAKYAT INDONESIA (PERSERO), TbK KANTOR CABANG KUDUS
}

\author{
Harlyna Kusumawati *) \\ Ida Savitri Kusmargiani **)
}

*) harlynakusumawati@gmail.com

\begin{abstract}
The study aimed to analyze the influence of brand image, tangible, reliability, and service portofolio on the customer satisfaction of Simpedes saving at PT Bank Rakyat Indonesia (Persero) Tbk. Kudus Branch Office. Data collection method used purposive sampling technique, with samples from 100 respondents. The analysis model used in this research is Linear Regression Analysis Model while the data analysis techniques using the F test, $t$ test and the coefficient of determination $\left(R^{2}\right)$. In addition, it also tests the quality of the data in the form of test validity and reliability, as well as a classical assumption test normality test, multicollinearity, heteroscedasticity test and autocorrelation test. Test data indicate that the data is valid and reliable and free from irregularities classical assumptions. The analysis and discussion showed that brand image, tangible, reliability, and service portofolio simulataniously significant influence on the customer satisfaction of Simpedes saving in PT Bank Rakyat Indonesia (Persero), Tbk Branch Office Kudus. Variable brand image, tangible, reliability, and service portofolio partially significant influence customer satisfaction of Simpedes saving in PT Bank Rakyat Indonesia (Persero), Tbk Branch Office Kudus.
\end{abstract}

Keywords : Customer Satisfaction, Brand Image, Tangible, Reliability, Service Portofolio.

*) Mahasiswa Tugas Akhir Prodi Keuangan dan Perbankan, Jurusan Akuntansi, Politeknik Negeri Semarang

**) Dosen Jurusan Akuntansi Politeknik Negeri Semarang

\section{PENDAHULUAN}

\section{Latar Belakang}

Lembaga keuangan seperti perbankan merupakan salah satu unsur lembaga keuangan yang berkewajiban menjalankan arus kegiatan di bidang ekonomi dan moneter. Perkembangan bank di Indonesia sekarang ini mengalami persaingan yang ketat, tidak hanya pada tingkat regional saja namun juga secara global, baik dalam segi kualitas pelayanan maupun promosi produk. Semakin ketatnya persaingan yang terjadi sekarang ini tidak hanya persaingan dengan sesama bank saja, namun dengan lembaga keuangan lain seperti asuransi, pegadaian, dan lainnya.

Menurut Kasmir (2012:3), bank adalah lembaga keuangan yang kegiatan utamanya adalah menghimpun dana dari masyarakat dan menyalurkannya kembali dana tersebut ke masyarakat serta memberikan jasa bank lainnya. Berdasarkan uraian tersebut dapat disimpulkan bahwa bank sebagai lembaga perantara keuangan dimana keberhasilan bank 
tergantung bagaimana bank tersebut merebut hati masyarakat, sehingga perannya sebagai lembaga perantara dapat berjalan dengan baik.

Salah satu bank terbesar di Indonesia yang turut bersaing di dunia perbankan adalah Bank BRI. Bank Rakyat Indonesia (BRI) adalah salah satu bank milik pemerintah yang terbesar di Indonesia. PT Bank Rakyat Indonesia (Persero) Tbk terus berupaya mengembangkan jaringan kerja yang tentunya didukung dengan kualitas pelayanan yang memadai, yang diharapkan dapat memberikan kepuasan kepada nasabah.

Berdasarkan hasil penelitian yang dilakukan melalui survey yang dilakukan oleh Frontier Consulting Group dengan mengukur tingkat kualitas produk perbankan Indonesia tahun 2017 dan 2018 dalam Top Brand Award dapat dilihat pada Tabel 1

Tabel 1 Top Brand Award Kategori Banking Finance Tahun 2017 dan 2018

\begin{tabular}{|c|l|c|l|l|}
\hline Peringkat & \multicolumn{1}{|c|}{ Tahun 2017 } & \multicolumn{1}{|c|}{ TBI } & \multicolumn{1}{|c|}{ Tahun 2018 } & TBI \\
\hline 1. & Tahapan BCA & $25,0 \%$ & Tahapan BCA & $34,9 \%$ \\
\hline 2. & BRI Simpedes & $\mathbf{1 5 , 5 \%}$ & BRI Britama & $20,2 \%$ \\
\hline 3. & BRI Britama & $13,2 \%$ & BRI Simpedes & $\mathbf{1 2 , 3 \%}$ \\
\hline 4. & BNI Taplus & $9,2 \%$ & Tabungan Mandiri & $9,2 \%$ \\
\hline 5. & Tabungan Mandiri & $7,6 \%$ & BNI Taplus & $6,6 \%$ \\
\hline
\end{tabular}

Sumber: www.topbrand-award.com (2017 dan 2018)

Berdasarkan hasil survey di atas, dapat dilihat bahwa produk tabungan Simpedes dari tahun 2017 ke tahun 2018 mengalami penurunan. Hal tersebut dapat dilihat yaitu pada tahun 2017 produk tabungan BRI Simpedes berada pada peringkat 2 dengan persentase Top Brand Index sebesar 15,5\%. Sedangkan pada tahun 2018 produk tabungan BRI Simpedes mengalami penurunan menjadi peringkat 3 dengan persentase Top Brand Index yang juga ikut menurun sebesar $3,2 \%$ yaitu menjadi $12,3 \%$.

PT Bank Rakyat Indonesia (Persero), Tbk Kantor Cabang Kudus telah melakukan berbagai upaya untuk meningkatkan peringkatnya, salah satunya yaitu dengan semakin meningkatkan penjualan produknya. Salah satu produk tabungan PT Bank Rakyat Indonesia (Persero), Tbk Kantor Cabang Kudus yang memiliki banyak peminat yaitu produk Tabungan Simpedes. Diperoleh data penjualan produk Tabungan Simpedes pada tahun 2017 dan 2018 yang dapat dilihat pada Tabel 2.

Tabel 2 Jumlah Saldo dan Nasabah Tabungan Simpedes PT Bank Rakyat Indonesia (Persero), Tbk Kantor Cabang Kudus

\begin{tabular}{|c|c|c|c|c|}
\hline Tahun & Target (Rp) & Realisasi (Rp) & $\begin{array}{c}\text { Presentase } \\
\text { Pencapaian }\end{array}$ & Jumlah Nasabah \\
\hline 2017 & 3.500 .000 .000 .000 & 2.326 .006 .702 .209 & $77,53 \%$ & 53.599 \\
\hline 2018 & 6.500 .000 .000 .000 & 4.967 .668 .031 .558 & $76,43 \%$ & 58.859 \\
\hline
\end{tabular}

Sumber: PT Bank Rakyat Indonesia (Persero), Tbk Kantor Cabang Kudus 
Berdasarkan tabel 2 dapat dilihat bahwa penjualan produk Tabungan Simpedes meningkat dari tahun 2017 sebanyak 53.599 dan tahun 2018 menjadi 58.859. Namun walaupun data jumlah nasabah Tabungan Simpedes dan jumlah saldo tabungan meningkat, pencapaian tersebut masih belum dapat memenuhi target yang diberikan oleh pihak bank. dimana target yang diberikan pada tahun 2017 yaitu Rp 3.500.000.000.000, sedangkan pada tahun 2018 sebesar Rp 6.500.000.000.000. Oleh karena itu PT Bank Rakyat Indonesia (Persero), Tbk Kantor Cabang Kudus perlu berusaha lagi untuk dapat meningkatkan pencapaiannya di tahun yang akan datang.

PT Bank Rakyat Indonesia (Persero), Tbk telah melakukan beberapa upaya untuk meningkatkan penjualan produknya salah satunya yaitu dengan meningkatkan kualitas pelayanan khususnya kualitas layanan tabungan. Namun usaha PT Bank Rakyat Indonesia (Persero), Tbk belum dilakukan secara optimal sehingga masih belum dapat memenuhi harapan nasabahnya. Hal tersebut dapat dibuktikan dengan masih adanya keluhan dari beberapa nasabah PT Bank Rakyat Indonesia (Persero), Tbk Kantor Cabang Kudus mengenai layanannya.

Tabel 3 Keluhan Nasabah Tabungan

PT. Bank Rakyat Indonesia (Persero) Tbk Kantor Cabang Kudus

\begin{tabular}{|c|l|}
\hline No. & \multicolumn{1}{|c|}{ Jenis Keluhan } \\
\hline 1 & ATM BRI sering mengalami gangguan (offline) \\
\hline 2 & $\begin{array}{l}\text { Tidak terdapat tempat duduk untuk menunggu antrean ketika akan bertransaksi di } \\
\text { Teller }\end{array}$ \\
\hline 3 & Pelayanan Customer Service yang kurang ramah \\
\hline 4 & Lambatnya waktu penanganan keluhan. \\
\hline
\end{tabular}

Sumber: Nasabah PT. Bank Rakyat Indonesia (Persero) Tbk Kantor Cabang Kudus yang diolah oleh penulis

Berdasarkan keluhan dari nasabah PT. Bank Rakyat Indonesia (Persero) Tbk Kantor Cabang Kudus tersebut menunjukkan bahwa nasabah masih kurang puas dengan pelayanan yang diberikan oleh PT. Bank Rakyat Indonesia (Persero) Tbk. Kantor Cabang Kudus. Jika hal tersebut masih terus berlanjut maka akan menimbulkan risiko bagi PT. Bank Rakyat Indonesia (Persero) Tbk Kantor Cabang Kudus mendatang serta bisa mengakibatkan berpindahnya nasabah ke bank lain yang pelayanannya lebih memuaskan. Berdasarkan uraian di atas penelitian ini difokuskan pada: "Analisis Pengaruh Citra Merek, Bukti Fisik, Keandalan, dan Jasa Portofolio Terhadap Kepuasan Nasabah Tabungan Simpedes pada PT Bank Rakyat Indonesia (Persero), Tbk Kantor Cabang Kudus". 


\section{KAJIAN TEORI}

\section{Citra Merek}

Menurut Rangkuty (2004 dalam Sondakh 2014) citra merek adalah sekumpulan asosiasi merek yang terbentuk dan melekat dibenak konsumen. Asosiasi atas organisasi seperti persepsi mengenai karyawan organisasi yang memberikan jasa cenderung menjadi asosiasi merek yang sangat penting yang mampu mempengaruhi evaluasi pelanggan atas mutu layanan secara langsung maupun tidak langsung (Kotler dan Keller, 2008:66).

Indikator yang digunakan pada penelitian ini merujuk pada Aaker dan Biel dalam jurnal Supriyadi, dkk (2016), yang dikembangkan dalam penelitian ini, yaitu sebagai berikut:

$\mathrm{X}_{1.1}$ : Ketersediaan ATM untuk tarik/setor tunai tabungan Simpedes di berbagai tempat

$\mathrm{X}_{1.2}$ : Kantor unit untuk melakukan transaksi tabungan Simpedes terdapat di berbagai tempat

$\mathrm{X}_{1.3}$ : Produk tabungan Simpedes memiliki desain yang menarik

$\mathrm{X}_{1.4}$ : Produk tabungan Simpedes memiliki fitur yang lengkap

$\mathrm{X}_{1.5}$ : Biaya administrasi tabungan Simpedes relatif murah

\section{Bukti Fisik}

Menurut Parasuraman, dkk (1998 dalam Lupiyoadi dan Hamdani, 2006:183) menyatakan Bukti fisik (tangible) yaitu kemampuan suatu perusahaan dalam menunjukkan eksistensinya kepada pihak eksternal. Penampilan dan kemampuan sarana dan prasarana fisik perusahaan yang dapat diandalkan keadaan lingkungan sekitarnya merupakan bukti nyata dari pelayanan yang diberikan oleh pemberi jasa. Dengan adanya bukti fisik, nasabah akan merasa nyaman berada di bank tanpa ada rasa bosan dan juga akan menarik minat nasabah terhadap fasilitas yang disediakan oleh bank.

Indikator yang digunakan dalam penelitian ini merujuk pada Bahia dan Nantel dalam jurnal Deccasari (2015) dan Sumardiningsih, dkk (2012) yang dikembangkan oleh penulis sebagai berikut:

$\mathrm{X}_{2.1}$ : Lokasi kantor untuk melakukan transaksi tabungan Simpedes strategis

$\mathrm{X}_{2.2}$ : Lingkungan kantor untuk melakukan transaksi tabungan Simpedes bersih

$\mathrm{X}_{2.3}$ : Kenyamanan ruang tunggu nasabah tabungan Simpedes

$\mathrm{X}_{2.4}$ : Petugas berpenampilan menarik dalam melayani nasabah tabungan Simpedes

\section{Kehandalan}

Menurut (Parasuraman, dkk, 1998) dalam Lupiyoadi (2006:183) menyatakan Kehandalan (reliability), yaitu kemampuan perusahaan untuk memberikan pelayanan sesuai 
dengan yang dijanjikan secara akurat dan terpercaya. Indikator yang digunakan dalam penelitian ini merujuk pada Bahia dan Nantel dalam jurnal Deccasari (2015) dan Sumardiningsih, dkk (2012) yang dikembangkan oleh penulis sebagai berikut:

$\mathrm{X}_{3.1}$ : Kemampuan petugas memberikan informasi tabungan Simpedes dengan jelas

$\mathrm{X}_{3.2}$ : Kemampuan petugas menginput data nasabah tabungan Simpedes dengan benar

$\mathrm{X}_{3.3}$ : Kemampuan petugas memberikan layanan tabungan Simpedes sesuai dengan waktu yang dijanjikan

$\mathrm{X}_{3.4}$ : Kemampuan petugas melakukan koreksi dengan cepat pada saat terjadi kesalahan pada data nasabah tabungan Simpedes

\section{Jasa Portofolio}

Menurut Bahia dan Nantel (2000 dalam Deccasari, 2015) jasa portofolio merupakan kelengkapan jasa yang diberikan pihak perbankan untuk kemudahan transaksi bagi nasabah seperti pembayaran listrik dan telepon melalui bank. Indikator yang digunakan dalam penelitian ini merujuk pada Bahia dan Nantel dalam jurnal Sumardiningsih, dkk (2012) yang dikembangkan oleh penulis sebagai berikut:

$\mathrm{X}_{4.1}$ : Ketersediaan layanan internet banking pada tabungan Simpedes

$\mathrm{X}_{4.2}$ : Ketersediaan layanan mobile banking pada tabungan Simpedes

$\mathrm{X}_{4.3}$ : Ketersediaan layanan setor tunai melalui ATM pada tabungan Simpedes

$\mathrm{X}_{4.4}$ : Ketersediaan layanan pembayaran melalui ATM pada tabungan Simpedes

\section{Kepuasan}

Menurut Kotler (1997 dalam Lupiyoadi dan Hamdani, 2006:192) kepuasan merupakan tingkat perasaan dimana seseorang menyatakan hasil perbandingan atas kinerja produk (jasa) yang diterima dan yang diharapkan. Dari keseluruhan kegiatan yang dilakukan oleh sebuah perusahaan pada akhirnya akan bermuara pada nilai yang akan diberikan oleh pelanggan mengenai kepuasan yang dirasakan. Jadi kepuasan atau ketidakpuasan adalah kesimpulan dari interaksi antara harapan dan pengalaman sesudah memakai jasa atau pelayanan yang diberikan, pelanggan yang puas juga cenderung akan memberikan refrensi yang baik terhadap produk jasa kepada orang lain Kotler (dalam Lupiyoadi dan Hamdani 2006: 194).

Indikator yang digunakan dalam penelitian ini merujuk pada jurnal Dewi, dkk (2012) yang dikembangkan oleh penulis sebagai berikut:

$\mathrm{Y}_{1}:$ Kepuasan atas merek tabungan Simpedes

$\mathrm{Y}_{2}$ : Kepuasan atas bukti fisik bank kepada nasabah tabungan Simpedes

$\mathrm{Y}_{3}:$ Kepuasan atas kemampuan petugas bank dalam memberikan layanan 
kepada nasabah tabungan Simpedes

$\mathrm{Y}_{4}:$ Kepuasan atas kelengkapan jasa pada tabungan Simpedes

\section{Kerangka Pemikiran Teoritis}

Kerangka pemikiran teoritis pada penelitian ini terlihat pada Gambar 1.

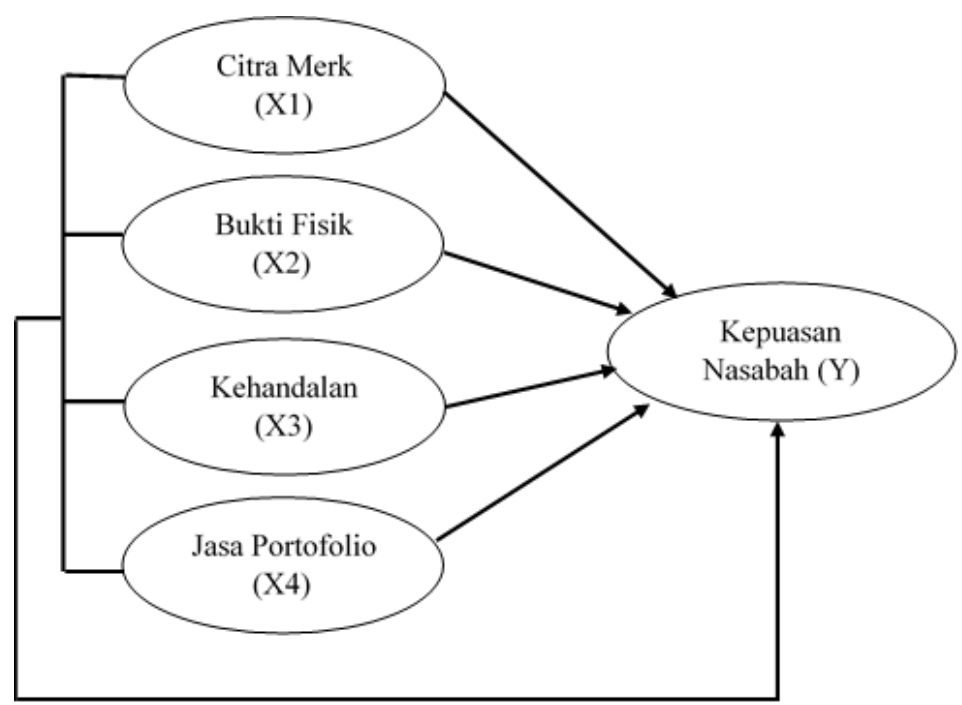

(Sumber: Penelitian terdahulu yang dikembangkan)

Gambar 1

\section{Hipotesis Penelitian}

\section{Kerangka Pemikiran Teoritis}

H1 = Diduga bahwa secara simultan variabel citra merek, bukti fisik, kehandalan, dan jasa portofolio berpengaruh signifikan terhadap kepuasan nasabah Tabungan Simpedes PT Bank Rakyat Indonesia (Persero) Tbk Kantor Cabang Kudus.

H2 = Diduga bahwa secara parsial variabel citra merek berpengaruh signifikan terhadap kepuasan nasabah Tabungan Simpedes PT Bank Rakyat Indonesia (Persero) Tbk Kantor Cabang Kudus.

H3 = Diduga bahwa secara parsial variabel bukti fisik berpengaruh signifikan terhadap kepuasan nasabah Tabungan Simpedes PT Bank Rakyat Indonesia (Persero) Tbk Kantor Cabang Kudus.

H4 = Diduga bahwa secara parsial variabel kehandalan berpengaruh signifikan terhadap kepuasan nasabah Tabungan Simpedes PT Bank Rakyat Indonesia (Persero) Tbk Kantor Cabang Kudus.

H5 = Diduga bahwa secara parsial variabel jasa portofolio berpengaruh signifikan terhadap kepuasan nasabah Tabungan Simpedes PT Bank Rakyat Indonesia (Persero) Tbk Kantor Cabang Kudus. 


\section{METODE PENELITIAN}

Desain penelitian yang digunakan dalam penelitian ini adalah penelitian kuantitatif kausal. Penelitian kuantitatif digunakan untuk meneliti populasi dan sampel tertentu, dengan mengumpulkan data menggunakan instrumen penelitian. (Sugiyono, 2016:8). Penelitian terapan digunakan untuk menemukan solusi bagi persoalan yang dihadapi. Penelitian terapan dapat disetarakan dengan penelitian kaji tindak (action research) yang dilakukan secara lebih teliti guna mempelajari perilaku dari variabel penelitian yang diamati di tempat berbeda dengan perlakuan berbeda pula, sehingga ditemukan jawaban untuk mengatasi permasalahan yang dihadapi (Wiyono, 2011:22). Sedangkan penelitian kausal digunakan untuk mengetahui hubungan antara dua variabel atau lebih yang bersifat sebab akibat. Artinya ada variabel yang mempengaruhi (variabel independen) dan ada variabel yang dipengaruhi (variabel dependen) (Wiyono, 2011:20).

Populasi dalam penelitian ini yaitu seluruh nasabah tabungan PT Bank Rakyat Indonesia (Persero), Tbk Kantor Cabang Kudus. Jumlah sampel sebanyak 100 responden. Teknik pengambilan sampel menggunakan purposive sampling.

Instrumen penelitian dalam penelitian ini menggunakan kuesioner dengan pertanyaan terbuka dan pertanyaan tertutup menggunakan skala likert mulai dari Sangat Tidak Setuju (STS), Tidak Setuju (TS), Setuju (S), dan Sangat Setuju (SS). Teknik analisis dengan menggunakan bantuan program software SPSS 25 yang terdiri dari Uji Instrumen Penelitian (Uji Validitas dan Uji Reliabilitas), Uji Asumsi Klasik (Uji Normalitas, Uji Multikolonieritas, Uji Heteroskedastisitas, dan Uji Autokorelasi), dan Uji Regresi Linear Berganda (Uji F, Uji t, dan Uji R).

\section{HASIL DAN PEMBAHASAN}

\section{Uji Instrumen Penelitian}

\section{Uji Validitas}

Hasil uji validitas menunjukkan bahwa $r_{\text {hitung }}$ dari semua indikator lebih besar dari $r_{\text {tabel }}$. Sehingga data kuesioner dalam penelitian ini valid. 
keunis Majalah Ilmiah - ISSN No 2302-9315 Vol. 8 No 2 Thn VIII Juli 2020

Tabel 4 Hasil Uji Validitas

\begin{tabular}{|l|c|c|c|c|c|}
\hline Variabel & Indikator & rhitung & rtabel & Sig & Keterangan \\
\hline Citra Merek $\left(\mathrm{X}_{1}\right)$ & $\mathrm{X}_{1.1}$ & 0,691 & 0,1966 & 0,000 & VALID \\
\cline { 2 - 6 } & $\mathrm{X}_{1.2}$ & 0,744 & 0,1966 & 0,000 & VALID \\
\cline { 2 - 6 } & $\mathrm{X}_{1.3}$ & 0,543 & 0,1966 & 0,000 & VALID \\
\cline { 2 - 6 } & $\mathrm{X}_{1.4}$ & 0,611 & 0,1966 & 0,000 & VALID \\
\cline { 2 - 6 } & $\mathrm{X}_{1.5}$ & 0,790 & 0,1966 & 0,000 & VALID \\
\hline \multirow{4}{*}{ Bukti Fisik $\left(\mathrm{X}_{2}\right)$} & $\mathrm{X}_{2.1}$ & 0,806 & 0,1966 & 0,000 & VALID \\
\cline { 2 - 6 } & $\mathrm{X}_{2.2}$ & 0,832 & 0,1966 & 0,000 & VALID \\
\cline { 2 - 6 } & $\mathrm{X}_{2.3}$ & 0,805 & 0,1966 & 0,000 & VALID \\
\cline { 2 - 6 } & $\mathrm{X}_{2.4}$ & 0,765 & 0,1966 & 0,000 & VALID \\
\hline \multirow{5}{*}{ Kehandalan $\left(\mathrm{X}_{3}\right)$} & $\mathrm{X}_{3.1}$ & 0,828 & 0,1966 & 0,000 & VALID \\
\cline { 2 - 6 } & $\mathrm{X}_{3.2}$ & 0,839 & 0,1966 & 0,000 & VALID \\
\cline { 2 - 6 } & $\mathrm{X}_{3.3}$ & 0,855 & 0,1966 & 0,000 & VALID \\
\cline { 2 - 6 } & $\mathrm{X}_{3.4}$ & 0,831 & 0,1966 & 0,000 & VALID \\
\hline Jasa Portofolio $\left(\mathrm{X}_{4}\right)$ & $\mathrm{X}_{4.1}$ & 0,811 & 0,1966 & 0,000 & VALID \\
\cline { 2 - 6 } & $\mathrm{X}_{4.2}$ & 0,842 & 0,1966 & 0,000 & VALID \\
\cline { 2 - 6 } & $\mathrm{X}_{4.3}$ & 0,886 & 0,1966 & 0,000 & VALID \\
\cline { 2 - 6 } & $\mathrm{X}_{4.4}$ & 0,819 & 0,1966 & 0,000 & VALID \\
\hline Kepuasan Nasabah (Y) & $\mathrm{Y}_{1}$ & 0,700 & 0,1966 & 0,000 & VALID \\
\cline { 2 - 6 } & $\mathrm{Y}_{2}$ & 0,461 & 0,1966 & 0,000 & VALID \\
\cline { 2 - 6 } & $\mathrm{Y}_{3}$ & 0,396 & 0,1966 & 0,000 & VALID \\
\cline { 2 - 6 } & $\mathrm{Y}_{4}$ & 0,460 & 0,1966 & 0,000 & VALID \\
\hline
\end{tabular}

(Sumber: Data primer yang diolah, 2019)

\section{Uji Reliabilitas}

Berdasarkan hasil uji reliabilitas menunjukkan bahwa nilai cronbach's alpha dari semua variabel lebih besar dari 0,70. Sehingga data dalam penelitian ini reliabel.

Tabel 5 Hasil Uji Reliabilitas

\begin{tabular}{|l|c|l|}
\hline \multicolumn{1}{|c|}{ Variabel } & Cronbach Alpha & Keterangan \\
\hline Citra Merek $\left(\mathrm{X}_{1}\right)$ & 0,703 & RELIABEL \\
\hline Bukti Fisik $\left(\mathrm{X}_{2}\right)$ & 0,814 & RELIABEL \\
\hline Kehandalan $\left(\mathrm{X}_{3}\right)$ & 0,858 & RELIABEL \\
\hline Jasa Portofolio $\left(\mathrm{X}_{4}\right)$ & 0,861 & RELIABEL \\
\hline Kepuasan Nasabah $(\mathrm{Y})$ & 0,812 & RELIABEL \\
\hline
\end{tabular}

(Sumber: Data primer yang diolah, 2019)

\section{Uji Asumsi Klasik}

\section{Uji Normalitas}

Dari uji normalitas menghasilkan nilai asymptotic significance sebesar 0,200 lebih besar dari 0,05 atau 5\%, sehingga variabel pengganggu atau residual memiliki distribusi normal. Dengan demikian model regresi layak digunakan untuk melakukan penelitian. 


\section{Uji Multikolinieritas}

Hasil perhitungan uji multikolonieritas menunjukkan bahwa semua variabel memiliki nilai Tolerance $\geq 0,10$ dan nilai VIF $\leq 10$. Hal ini menunjukkan tidak ada multikolinieritas antar variabel independen dalam model regresi.

\section{Uji Heteroskedastisitas}

Berdasarkan uji heteroskedastisitas dengan jelas menunjukkan bahwa tidak ada satupun variabel independen yang signifikan secara statistik mempengaruhi variabel dependen nilai Absolut Res (ABS_RES). Hal ini terlihat dari probabilitas signifikansi diatas 5\% atau 0,05. Jadi dapat disimpulkan model regresi tidak terdapat heteroskedastisitas.

\section{Uji Autokorelasi}

Berdasarkan uji autokorelasi diperoleh persamaan: 1,7582 (du) $<1,839$ (DW) $<2,2418$ (4-du). Dari persamaan tersebut maka dapat disimpulkan bahwa tidak ada autokorelasi positif dan negatif, artinya tidak terdapat autokoralasi pada model regresi ini.

\section{Hasil Uji F (Simultan)}

Hasil uji F menunjukkan bahwa secara bersama-sama variabel citra merek, bukti fisik, kehandalan, dan jasa portofolio berpengaruh signifikan terhadap kepuasan nasabah tabungan Simpedes pada PT Bank Rakyat Indonesia (Persero), Tbk Kantor Cabang Kudus. Hal ini terjadi karena dari hasil uji $\mathrm{F}$ menunjukkan bahwa $F_{\text {hitung }}$ 71,097 lebih besar dari $F_{\text {tabel }}$ 2,47 atau nilai signifikansi 0,000 lebih kecil dari 0,05. Berdasarkan hasil uji F ini, dapat diambil kesimpulan bahwa hipotesis 1 dinyatakan diterima.

\section{Uji t (Parsial)}

Berdasarkan hasil pengujian uji t, diperoleh nilai thitung dari variabel citra merek sebesar 6,777 , nilai thitung dari variabel bukti fisik sebesar 6,465 , nilai thitung dari variabel kehandalan sebesar 6,927, nilai thitung dari variabel jasa portofolio sebesar 9,186. Keempat variabel tersebut memiliki nilai $t_{\text {hitung }}$ lebih besar dari $t_{\text {tabel }}$ yaitu 1,985. Hal ini menunjukkan bahwa hipotesis 2 , hipotesis 3, hipotesis 4, dan hipotesis 5 dinyatakan diterima.

\section{Uji Koefisien Determinasi $\left(\mathbf{R}^{2}\right)$}

Besarnya nilai koefisien determinasi (Adjusted $R^{2}$ ) dalam penelitian ini sebesar 0,739 . Hal ini menunjukkan bahwa variabel citra merek, bukti fisik, kehandalan, dan jasa portofolio dalam menjelaskan kepuasan nasabah sebesar 73,9\% dan sisanya 26,1\% dipengaruhi oleh variabel lain yang tidak diteliti dalam penelitian ini. 


\section{KESIMPULAN DAN SARAN}

\section{Kesimpulan}

Berdasarkan hasil pengujian statistik untuk menguji pengaruh citra merek, bukti fisik, kehandalan, dan jasa portofolio terhadap kepuasan nasabah tabungan Simpedes pada PT Bank Rakyat Indonesia (Persero), Tbk Kantor Cabang Kudus, maka peneliti dapat mengambil kesimpulan sebagai berikut:

1. Citra merek, bukti fisik, kehandalan, dan jasa portofolio secara simultan berpengaruh signifikan terhadap kepuasan nasabah pada PT Bank Rakyat Indonesia (Persero), Tbk Kantor Cabang Kudus.

2. Citra merek secara parsial berpengaruh signifikan terhadap kepuasan nasabah pada PT Bank Rakyat Indonesia (Persero), Tbk Kantor Cabang Kudus.

3. Bukti fisik secara parsial berpengaruh signifikan terhadap kepuasan nasabah pada PT Bank Rakyat Indonesia (Persero), Tbk Kantor Cabang Kudus.

4. Kehandalan secara parsial berpengaruh signifikan terhadap kepuasan nasabah pada PT Bank Rakyat Indonesia (Persero), Tbk Kantor Cabang Kudus.

5. Jasa portofolio secara parsial berpengaruh signifikan terhadap kepuasan nasabah pada PT Bank Rakyat Indonesia (Persero), Tbk Kantor Cabang Kudus.

\section{Implikasi}

\section{Impliasi Teoritis}

Implikasi teoritis dalam penelitian ini dikembangkan untuk memperkuat dukungan atas beberapa penelitian terdahulu. Variabel citra merek berpengaruh signifikan terhadap kepuasan nasabah tabungan Simpedes pada PT Bank Rakyat Indonesia (Persero), Tbk Kantor Cabang Kudus. Hasil penelitian ini sejalan dengan hasil penelitian terdahulu yang dilakukan oleh Tombokan, dkk (2015) dan Kurniawati, dkk (2014). Variabel bukti fisik berpengaruh signifikan terhadap kepuasan nasabah tabungan Simpedes pada PT Bank Rakyat Indonesia (Persero), Tbk Kantor Cabang Kudus. Hasil penelitian ini sejalan dengan hasil penelitian terdahulu yang dilakukan oleh Wahab (2017) dan Mulyaningsih dan Suasana (2016). Variabel kehandalan berpengaruh signifikan terhadap kepuasan nasabah tabungan Simpedes pada PT Bank Rakyat Indonesia (Persero), Tbk Kantor Cabang Kudus. Hasil penelitian ini sejalan dengan hasil penelitian terdahulu yang dilakukan oleh Wahab (2017) dan Yulianti (2013). Variabel jasa portofolio berpengaruh signifikan terhadap kepuasan nasabah tabungan Simpedes pada PT Bank Rakyat Indonesia (Persero), Tbk Kantor Cabang Kudus. Hasil penelitian ini sejalan dengan hasil penelitian terdahulu yang dilakukan oleh Astuti (2015) dan Sumardiningsih, dkk (2012). 


\section{Implikasi Manajerial}

Implikasi Manajerial fokus terhadap variabel-variabel yang mempunyai urutan pengaruh signifikan yang paling kuat dalam meningkatkan kepuasan nasabah tabungan Simpedes yaitu jasa portofolio, kehandalan, citra merek, dan bukti fisik. Berikut ini akan dijabarkan implikasi manajerial yang bisa diberikan kepada pihak manajemen PT Bank Rakyat Indonesia (Persero), Tbk. Kantor Cabang Kudus dengan urutan tertinggi terhadap kepuasan nasabah tabungan Simpedes berdasarkan tingkat signifikansi dan dikombinasikan dengan rekomendasi dari open question, adalah sebagai berikut:

1. Variabel jasa portofolio memiliki pengaruh yang signifikan terhadap kepuasan nasabah pada PT Bank Rakyat Indonesia (Persero) Tbk. Kantor Cabang Kudus. Oleh karena itu PT Bank Rakyat Indonesia (Persero) Tbk. Kantor Cabang Kudus harus mempertahankan jasa portofolio seperti meningkatkan dan menambah fitur ATM, layanan internet banking dan mobile banking, memperbanyak ATM setor tunai di berbagai tempat agar memudahkan nasabah dalam melakukan transaksi.

2. Variabel kehandalan memiliki pengaruh yang signifikan terhadap kepuasan nasabah pada PT Bank Rakyat Indonesia (Persero) Tbk. Kantor Cabang Kudus. Oleh karena itu PT Bank Rakyat Indonesia (Persero) Tbk. Kantor Cabang Kudus harus mempertahankan kehandalan seperti melatih kemampuan petugas dalam memberikan pelayanan yang ramah, sopan dan antusias kepada nasabah supaya dapat memberikan informasi dengan jelas, benar, tepat waktu dan cekatan dalam mengoreksi jika terjadi kesalahan.

3. Variabel citra merek memiliki pengaruh yang signifikan terhadap kepuasan nasabah pada PT Bank Rakyat Indonesia (Persero) Tbk. Kantor Cabang Kudus. Oleh karena itu PT Bank Rakyat Indonesia (Persero) Tbk. Kantor Cabang Kudus harus mempertahankan citra merek dengan cara menambah ketersediaan ATM di berbagai tempat, meskipun ATM PT Bank Rakyat Indonesia (Persero) Tbk. Kantor Cabang Kudus sudah cukup banyak, akan tetapi alangkah lebih baiknya jika menambah lagi ketersediaan ATM di berbagai tempat. Citra merek juga dapat dipertahankan dengan cara memperbanyak kantor unit supaya nasabah mudah menjangkau. Selain itu citra merek dapat ditingkatkan lagi dengan cara mengurangi biaya administrasi agar lebih terjangkau serta menambah variasi produk tabungan simpedes seperti halnya produk tabungan britama agar lebih menarik nasabah.

4. Variabel bukti fisik memiliki pengaruh yang signifikan terhadap kepuasan nasabah pada PT Bank Rakyat Indonesia (Persero) Tbk. Kantor Cabang Kudus. Oleh karena itu PT Bank Rakyat Indonesia (Persero) Tbk. Kantor Cabang Kudus harus mempertahankan 
bukti fisik seperti lokasi kantor yang sudah strategis, memperhatikan penampilan karyawan agar terlihat menarik, serta menjaga kebersihan dan kenyamanan lingkungan kantor, walaupun ada yang masih harus ditingkatkan lagi supaya meningkatkan kepuasan nasabah yaitu dengan menambah kursi untuk antrian teller agar nasabah lebih nyaman dalam mengantri.

\section{Keterbatasan Penelitian}

Keterbatasan penelitian ini adalah jumlah sampel yang digunakan hanya 100 karena keterbatasan waktu, tenaga serta biaya yang dikeluarkan untuk melakukan penelitian. Serta pada hasil uji koefisien determinasi pada bab sebelumnya menunjukkan bahwa terdapat $26,1 \%$ variabel yang mempengaruhi kepuasan nasabah namun tidak diteliti dalam penelitian ini.

\section{DAFTAR PUSTAKA}

Astuti, Dewi Setyorini. 2015. Analisis Pengaruh Banking Service Quality Dimensions (BSQ) Terhadap Kepuasan Nasabah PT Bank Jatim Cabang Jember. Artikel Ilmiah Mahasiswa. Bank Indonesia. 1998. Undang-Undang Republik Indonesia No. 10 Tahun 1998 Tentang Perbankan.

Deccasari, Dwi Danesty. 2015. Analisis Banking Service Quality Terhadap Citra Bank Syariah di Kota Malang. Jurnal JIBEKA. Vol. 9. No. 1.

Dewi, Nila Kasuma, Gus Andri dan Sepris Yonaldi. 2012. Pengaruh Iklan, Citra Merek, dan Kepuasan Konsumen Terhadap Loyalitas Konsumen dalam Menggunakan Vaseline Hand and Body Lotion di Kota Padang (Studi Kasus di PT Unilever Cabang Padang). Jurnal Manajemen dan Kewirausahaan. Vol. 3. No. 2. ISSN:2086-5031.

Ghozali, Imam. 2007. Aplikasi Analisis Multivariate dengan Program SPSS. Semarang: Badan Penerbit UNDIP.

2018. Aplikasi Analisis Multivariate dengan Program IBM SPSS 25.

Semarang: Badan Penerbit UNDIP.

Jaya, Ichwanul. 2014. Pengaruh Disiplin Pegawai dan Lingkungan Kerja Terhadap Kinerja Aparatur Kelurahan di Kecamatan Tanjung Redeb Kabupaten Berau. Jurnal Administrasi Publik dan Birokrasi. Vol. 1. No.3.

Kasmir. 2012. Dasar-Dasar Perbankan. Jakarta: Rajawali Press.

Kotler, Philip dan Kevin Lane Keller. 2008. Manajemen Pemasaran. Jakarta: PT. Indeks. Kurniawati, Dewi, Duharyono dan Andriani Kusumawati. 2014. Pengaruh Citra Merek dan Kualitas Produk Terhadap Kepuasan dan Loyalitas Pelanggan (Studi pada Pelanggan KFC Cabang Kawi Malang). Jurnal Administrasi Bisnis (JAB). Vol. 14. No. 2. 
Lupiyoadi, Rambat dan A. Hamdani. 2006. Manajemen Pemasaran Jasa. Edisi 2. Jakarta: Salemba Empat.

Infobank. 2018. "Pelayanan Prima". Jakarta: Mei.

Marzuki. 2005. Metodologi Riset. Edisi Kedua. Yogyakarta: Bagian Penerbit Fakultas Ekonomi Universitas Islam Indonesia Yogyakarta.

Mulyaningsih, Luy Ayu dan I Gst Agung Ketut Gede Suasana. Pengaruh Kualitas Layanan dan Citra Perusahaan Terhadap Kepuasan Nasabah pada Bank OCBC NISP di Denpasar. 2016. E-Jurnal Manajemen Unud. Vol. 5. No. 1. ISSN: 2302-8912.

Panjaitan, Januar Effendi. Pengaruh Kualitas Pelayanan Terhadap Kepuasan Nasabah pada JNE Cabang Bandung. 2016. DeReMa Jurnal Manajemen Vol. 11, No. 2, September 2016.

Sari, Muti Yunita. Analisis Pengaruh Banking Service Quality Dimensions (BSQ) Terhadap Kepuasan Nasabah Serta Dampaknya Terhadap Loyalitas Nasabah Studi pada PT Bank Rakyat Indonesia (Persero) Tbk. di Kota Semarang. 2013. Dokumen Karya Ilmiah Udinus.

Simamora, Bilson. 2004. Riset Pemasaran. Jakarta: PT Gramedia Pustaka Utama

Sondakh, Conny. 2014. Kualitas Layanan, Citra Merek dan Pengaruhnya Terhadap Kepuasan Nasabah dan Loyalitas Nasabah Tabungan (Studi pada Nasabah Taplus BNI Cabang Manado). Jurnal Bisnis Riset dan Manajemen. Vol. 3. No. 1.

Sugiyono. 2016. Metode Penelitian Kuantitatif, Kualitatif dan $R \&$ D. Bandung: Penerbit Alfabeta.

Sumardiningsih, Sri, Wawan Sundawan Lies Endarwati, Arif Wibowo dan Yulia Ayriza. 2012.

Pengaruh Dimensi Banking Service Quality (BSQ) Terhadap Kepuasan Nasabah Bank. Jurnal Economia. Vol. 8. No. 2.

Tjiptono, Fandy. 2007. Pemasaran Jasa. Malang: Bayumedia Publishing

Tombokan, Lotje Kawet dan Yantje Uhing. 2015. Pengaruh Kualitas Pelayanan, Citra Merek Terhadap Kepuasan Konsumen Pengguna Taplus BNI Kantor Cabang Utama Manado. Jurnal EMBA. Vol. 3. No. 3. ISSN: 2303-11.

Wahab, Wirdayani. 2017. Pengaruh Kualitas Pelayanan Terhadap Kepuasan Nasabah Industri Perbankan Syariah Di Kota Pekanbaru. Jurnal Kajian Ekonomi Islam. Vol. 2 No. 1.

Widjoyo, Iksan Ongko, Leonid Junivan Rumambi dan Yohanes Sondang Kunto. 2013. Analisa Pengaruh Kualitas Layanan Terhadap Kepuasan Leonid Konsumen pada Layanan Drive Thru Mc. Donald's Basuki Rahmat di Surabaya. Jurnal Manajemen Pemasaran. Vol. 1. No. 1. 
keunis Majalah IImiah - ISSN No 2302-9315 Vol. 8 No 2 Thn VIII Juli 2020

Wiyono, Gendro. 2011. 3 in One Merancang Penelitian Bisnis dengan Alat Analisis SPSS 17.0 \& SmartPls 2.0. Yogyakarta : UPP STIM YKPN.

www.bri.co.id. Diakses pada tanggal 19 Januari 2019.

www.topbrand-awards.com

Yulianti, Fadma. 2013. Pengaruh Kualitas Pelayanan Terhadap Kepuasan Nasabah Tabungan pada Bank Panin Tbk. KCP A. Yani Banjarmasin. Jurnal Spread. Vol. 3. No. 2. 